\title{
AZIË IN AMSTERDAM, LUXE IN DE GOUDEN EEUW
}

De grote najaarstentoonstelling van het Rijksmuseum gaat dit jaar over Aziatische luxegoederen in de $17^{\mathrm{e}}$-eeuwse Republiek: porselein en zijde uit China, lakwerk uit Japan, sitsen uit India, ivoren kistjes uit Ceylon. Plotseling was het verkrijgbaar, konden meer mensen dan voorheen het betalen en wilden meer mensen dan ooit het hebben.

Zoals bekend waren de Nederlandse kooplieden niet de eerste Europeanen die handel dreven in Azië en luxegoederen naar het noorden verscheepten. De Portugezen en Spanjaarden gingen hen voor. Kenmerkend voor de Nederlandse handel is de sterke vergroting van het volume. Veel meer porselein dan voorheen arriveerde in Europa en het varieerde sterk in kwaliteit. Dat betekende dat ook mensen met een smalle beurs zich een enkel stuk of een klein groepje porselein konden permitteren. Porselein veranderde daardoor van zeer exclusieve verzamelaarsobjecten in semi-luxuries, bereikbare en betaalbare hebbedingen. Juist door die bereikbaarheid en betaalbaarheid waren zoveel mensen geïnteresseerd en ging Azië zo'n grote rol spelen in de Nederlandse cultuur, samenleving en verbeelding.

Een direct gevolg van die brede toegankelijkheid en de populariteit van de Aziatische luxegoederen is dat kennis van kwaliteit belangrijker werd. Wie zich in de $17^{\mathrm{e}}$ eeuw wilde onderscheiden door zijn bezit aan porselein of lakwerk, kon dit alleen doen als hij goede, bijzondere en fraaie stukken had. Dit gevoel voor kwaliteit onder de $17^{\mathrm{e}}$-eeuwse liefhebbers is onder meer te volgen in de stillevens in de tentoonstelling. Wie goed kijkt, ziet dat de schilders niet zomaar een kom of een bordje afbeeldden, maar dat zij steeds met zorg voorwerpen kozen van hoge kwaliteit: strak gevormd, met een dunne wand en een stralend glazuur (afb. 1). Die kwaliteit valt op wanneer men dit porselein vergelijkt met de doorsnee van porseleinvondsten uit een $17^{\mathrm{e}}$-eeuwse beerput - een afspiegeling van de brede interesse en de variëteit aan kwaliteit. Schilders waren gegrepen door het materiaal porselein en wilden de kwaliteit ervan, de hardheid, de glans, het blauw, de bijna doorschijnende dunheid zo goed mogelijk weergeven. Zij keken en kozen dus

Afb. 1

Detail uit: Floris van Dijck, Stilleven met kazen, olieverf op doek, $82,2 \times 111,2 \mathrm{~cm}$., Nederland, ca. 1615 , Rijksmuseum Amsterdam, inv.nr. SK-A-4821. Gekocht met steun van de Vereniging Rembrandt zeer nauwkeurig.

In een embleem van Jan de Brune komt de kwestie van kwaliteit ook aan de orde (afb. 2). De boodschap is dat je vooraf zorgvuldig moet bepalen of de mensen met wie je wil omgaan wel deugen. Om dit proces te verduidelijken maakte de Brune een vergelijking met de beoordeling van porselein: 'De man, eer dat hij koopt, om niet te zijn bedrogen, / Hij knipt aen 't postuleyn: het mocht misschien niet dogen: / En hoort zoo aen 't geluyd, of 't fijn is naer zijn keur, / of 't niet te lomp en is, of ergens heeft een scheur.' Het is duidelijk: je

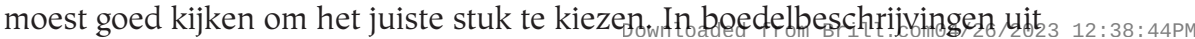


Afb. 2

Jan de Brune, embleem uit Emblemata of Zinnewerck, Amsterdam, Jan Evertsen Kloppenburch, tweede vermeerderde druk, 1636

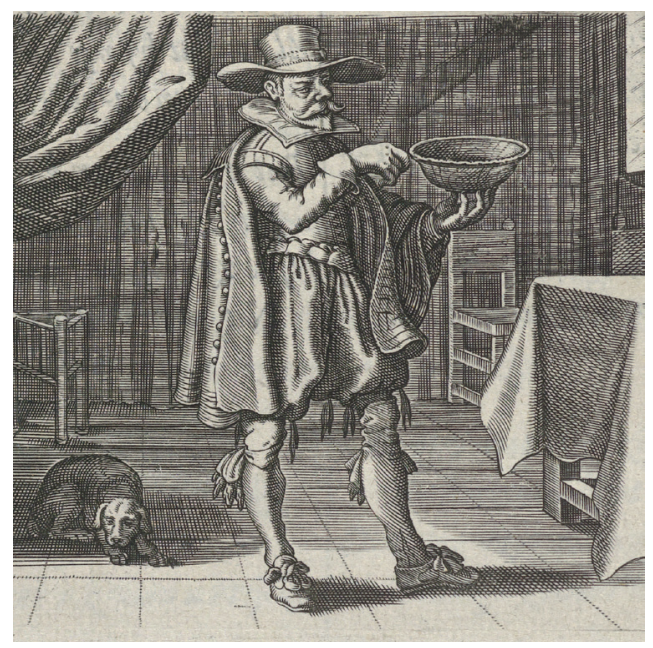

de $17^{\mathrm{e}}$ eeuw valt op dat taxatiewaarden van porselein flink uiteen konden lopen, ook binnen één boedel. Waarschijnlijk heeft dit alles te maken met die verschillen in kwaliteit en onderstreept dit het belang dat de liefhebbers hechtten aan het bezit van de beste stukken.

In de tentoonstelling hebben we het voorbeeld van de kritische $17^{\mathrm{e}}$-eeuwer gevolgd. We hebben geprobeerd Aziatische luxegoederen van het hoogste niveau bijeen te brengen om op die manier duidelijk te maken hoe exclusief die beste kwaliteit was en hoe belangrijk het moet zijn geweest juist díe stukken te bezitten. Bij het lakwerk zijn we hierin het beste geslaagd. Twee jaar geleden heeft het Rijksmuseum een grote kist van Japans lakwerk gekocht, zonder twijfel het beste in zijn soort dat in de $17^{\mathrm{e}}$ eeuw te koop was (afb. 3 en 4$){ }^{1}$

In de tentoonstelling maakt deze kist deel uit van een groep lakwerk, van hetzelfde hoge niveau, en daaronder zijn stukken waarvan precies bekend is voor wie ze in Japan zijn gekocht: voor Maria van Diemen, de vrouw van gouverneur-generaal Antonio van Diemen, de hoogste VOC-dienaar in Azië, en voor gouverneur-generaal Cornelis van der Lijn, Van Diemens opvolger. Dankzij hun contacten hadden zij toegang tot het atelier dat gewend was voor de shogun te werken, en konden zij daar hun bestellingen plaatsen. Dat was een prestatie van formaat en lukte slechts een paar keer in de periode omstreeks 1635-45. Van der Lijn en Van Diemen waren 'self made men' die in een bescheiden rang naar Azië waren gevaren en daar snel carrière hadden gemaakt. De gouverneur-generaals in Batavia leefden als vorsten, en moesten dat ook doen om serieus genomen te worden door de Aziatische heersers om hen heen. Dit lakwerk droeg zonder twijfel bij aan hun vorstelijke uitstraling. Na repatriëring werd de allure van de stukken in Europa zonder moeite herkend. Kort nadat de kist in Nederland arriveerde kocht een agent van kardinaal Mazarin het stuk voor diens collectie in Parijs. Mazarin was eerste minister van Frankrijk en de grootste en meest kieskeurige kunstverzamelaar van Europa. In zijn verzameling was de kist op zijn plaats en de bestemming, juist daar, laat zien hoe goed liefhebbers kwaliteit herkenden en waardeerden. 


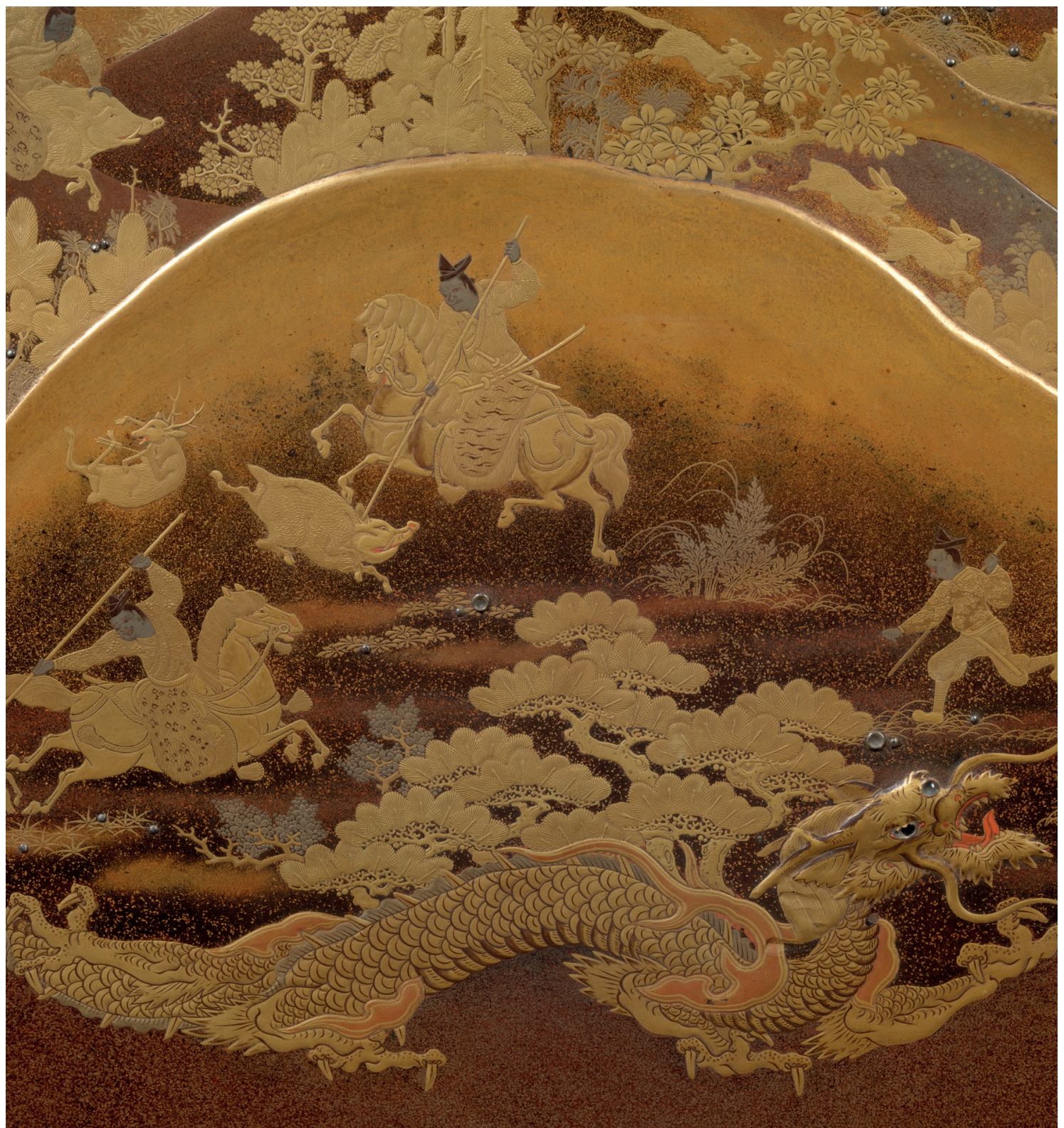

Afb. 3

Detail uit de kist,

afbeelding 4
Afb. $4>$

'Amsterdam kist', hout met lakwerk, h. 63,5 cm., br. $114,5 \mathrm{~cm}$, d. $73 \mathrm{~cm}$., Japan, 1635-45, Rijksmuseum Amsterdam, inv.nr.

AK-RAK-2013-3

Gekocht met steun van JT International Company Netherlands BV, de BankGiro Loterij, de Vereniging Rembrandt en de Jaffé-Pierson Stichting 


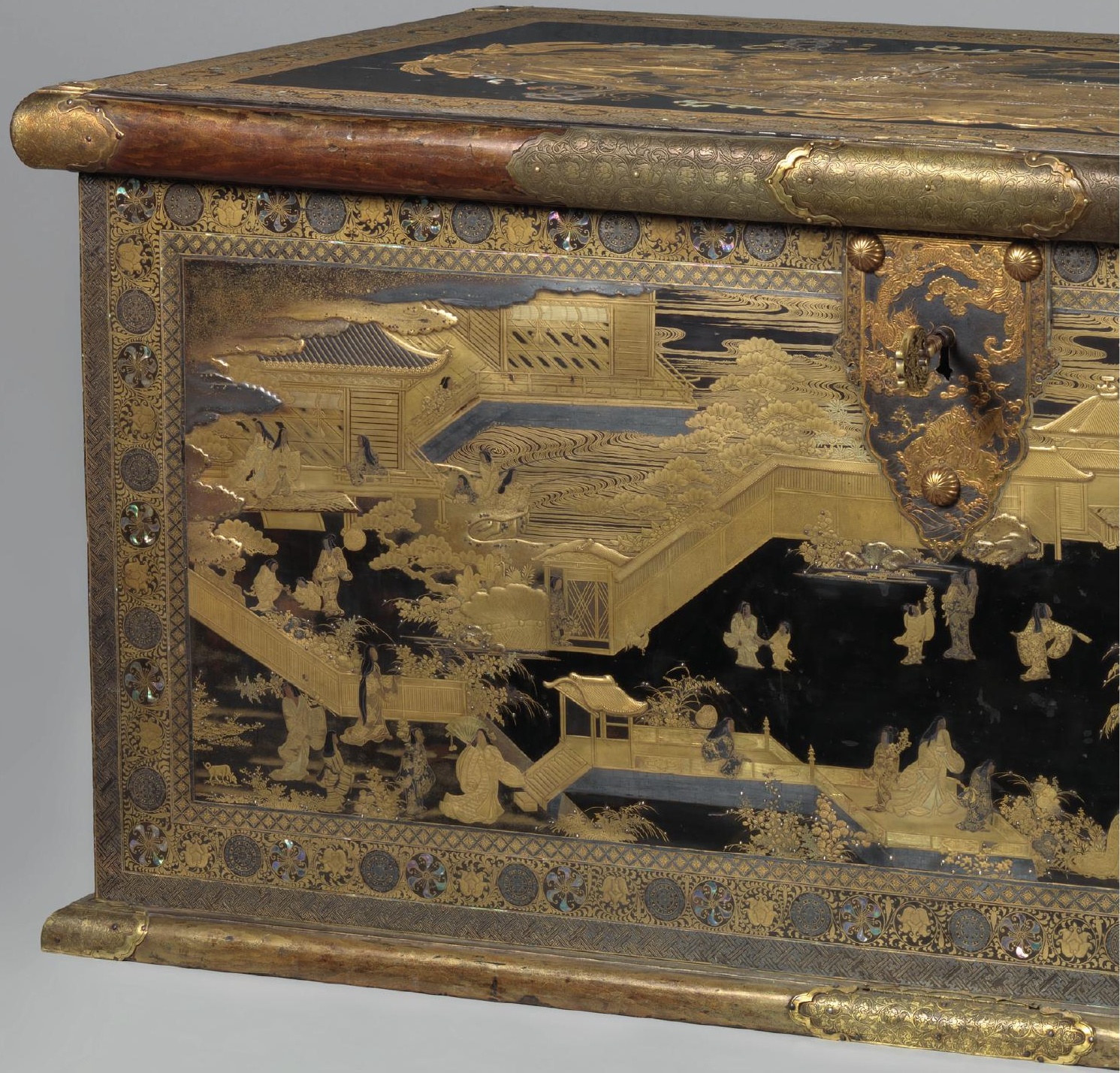




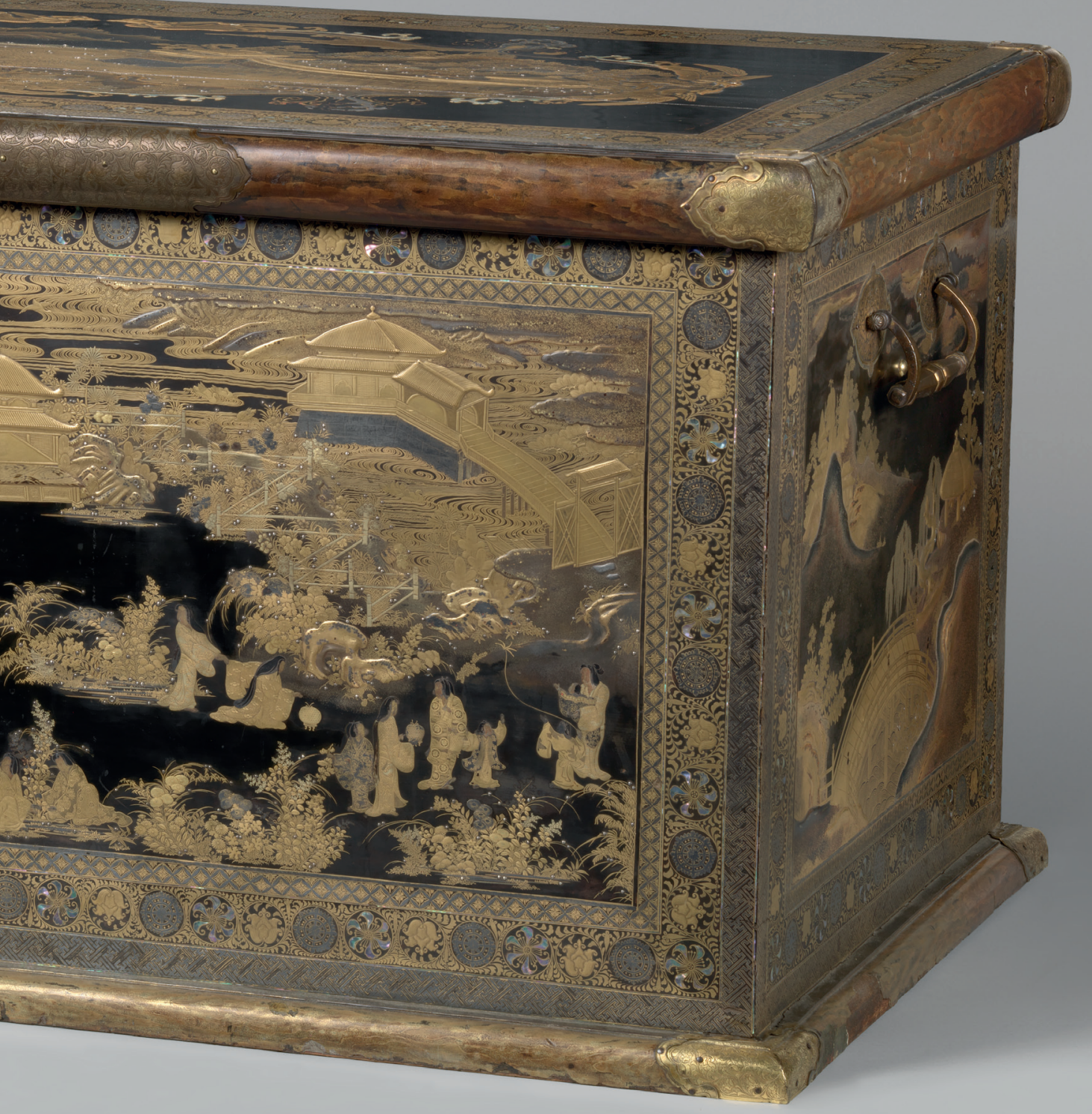




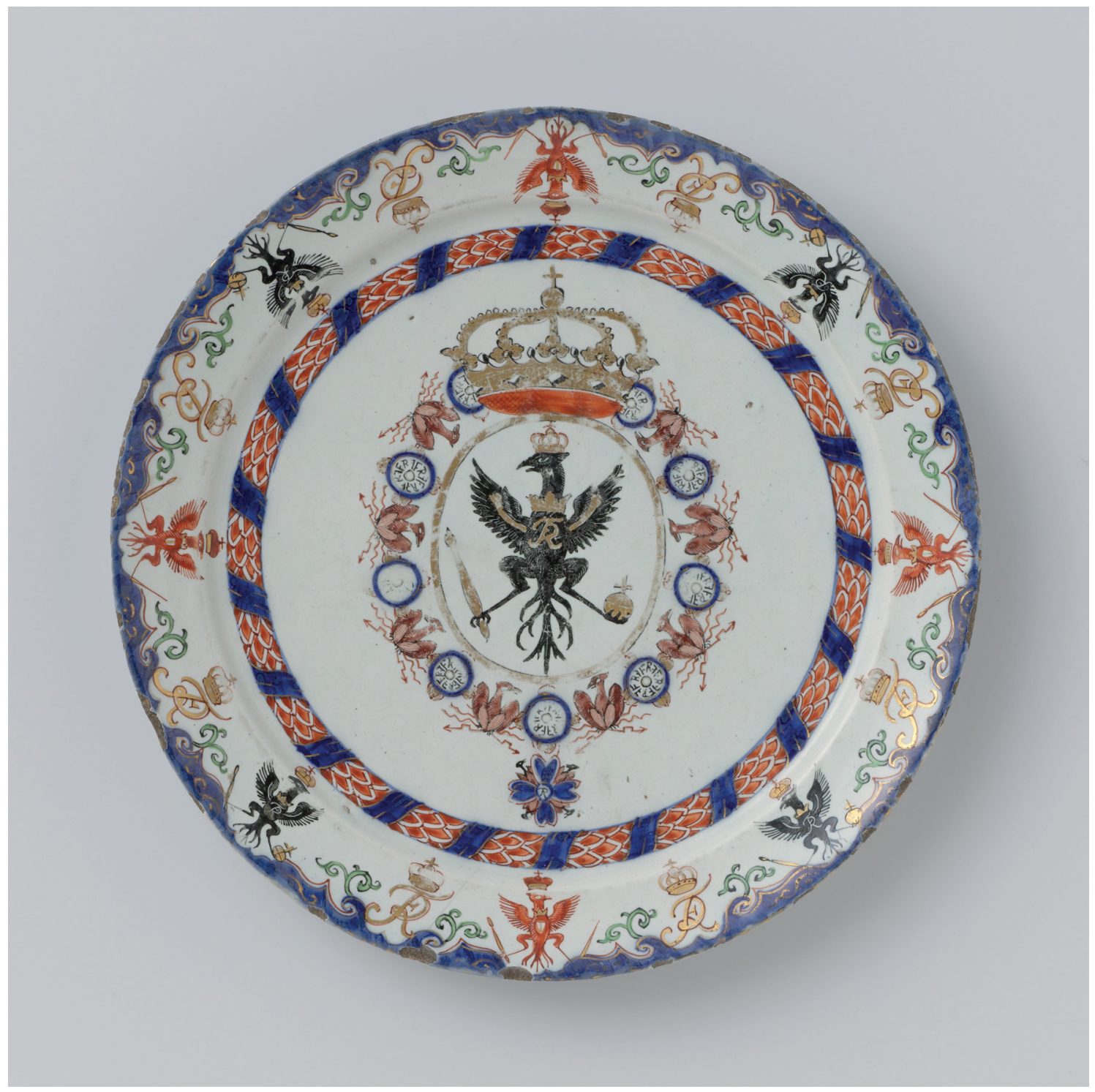

Afb. 5

Plateelfabriek de

Grieksche A, bord met

het wapen van koning

Frederick I van Pruisen,

tinglazuur aardewerk,

diam. $22 \mathrm{~cm}$. Delft,

1701-1722, Rijksmuseum

Amsterdam, inv.nr.

BK-1963-45 
Deze kist was dus niet zomaar een fraai meubelstuk, het was een opzienbarend kunstobject. Ook al is de informatie over opdrachtgever, eigenaar en verzamelaar niet vaak meer voorhanden, toch zal voor de bijzondere stukken porselein, lakwerk, sits en gesneden ivoor hetzelfde hebben gegolden. Door de toegenomen handel met Azië was er veel om uit te kiezen en dit zijn de stukken waar het meest verwende oog op viel.

In de tentoonstelling laten we deze fraaie stukken zien in combinatie met schilderijen waarop deze voorwerpen staan afgebeeld, en met het werk van Nederlandse kunstnijveraars die in een Aziatische stijl werkten. De Delftse pottenbakkers zijn daarvan het bekendste voorbeeld, maar daarnaast maakte de Amsterdammer Willem Kick al in 1609 lakwerk dat naar zijn eigen idee en dat van zijn klanten, kon wedijveren met het Japanse origineel. Amsterdamse zijdeweverijen vormden een bloeiende tak van nijverheid die stoffen produceerde voor de Nederlandse en Europese kopers. Dit werk van Nederlandse schilders en nijveraars geeft een extra inzicht in de betekenis van die plotse beschikbaarheid van de Aziatische producten. Het werk van de Nederlandse schilders stipte ik al aan. Het is opvallend hoeveel stillevens er vanaf circa 1610 zijn gemaakt waarin de schilders de kwaliteiten van het porselein probeerden te vangen. We kunnen in het werk van de Delftse plateelschilders zien hoe de toestroom van het Chinese porselein hen inspireerde. Zij namen Chinese motieven over, maar pasten steeds kleine en later grotere wijzigingen toe om het beter op de wensen van de klanten te laten aansluiten. Deze Delftse stukken laten dus zien hoe naar hun idee porselein er eigenlijk uit had moeten zien (afb. 5).

De fascinatie voor Azië blijkt ook uit het grote aantal reisverslagen en beschrijvingen van verre landen die Nederlandse uitgevers publiceerden en die een breed publiek bereikten. Al deze ingrediënten samen zorgden ervoor dat 'Azië' in de loop van de $17^{\mathrm{e}}$ eeuw 'overal' aanwezig was in Nederland. Het was een beeld van Azië, (hoe zou het kunnen en wat zou het zijn?) uiteraard geen objectief beeld maar een interessante fata morgana die tot stand was gekomen door de selectie van goederen die Nederlandse kooplieden aanvoerden en door het werk van Nederlandse kunstenaars, nijveraars en uitgevers, een beeld dat zich vanuit Nederland over Europa verspreidde en een lang leven zou hebben.

Azië in Amsterdam laat dit alles zien op de bovenverdieping van de Philipsvleugel, de tentoonstellingsvleugel van het Rijksmuseum.

- AZIË > AMSTERDAM. LUXE IN DE GOUDEN EEUW

Rijksmuseum, Amsterdam - 17 oktober 2015 t/m 17 januari 2016

\section{Noot}

1. Jan van Campen en Menno Fitski, Nieuwe aanwinst: de Mazarin kist in het Rijksmuseum, Aziatische Kunst 43-3/4 (2013), pp. 81-4. 


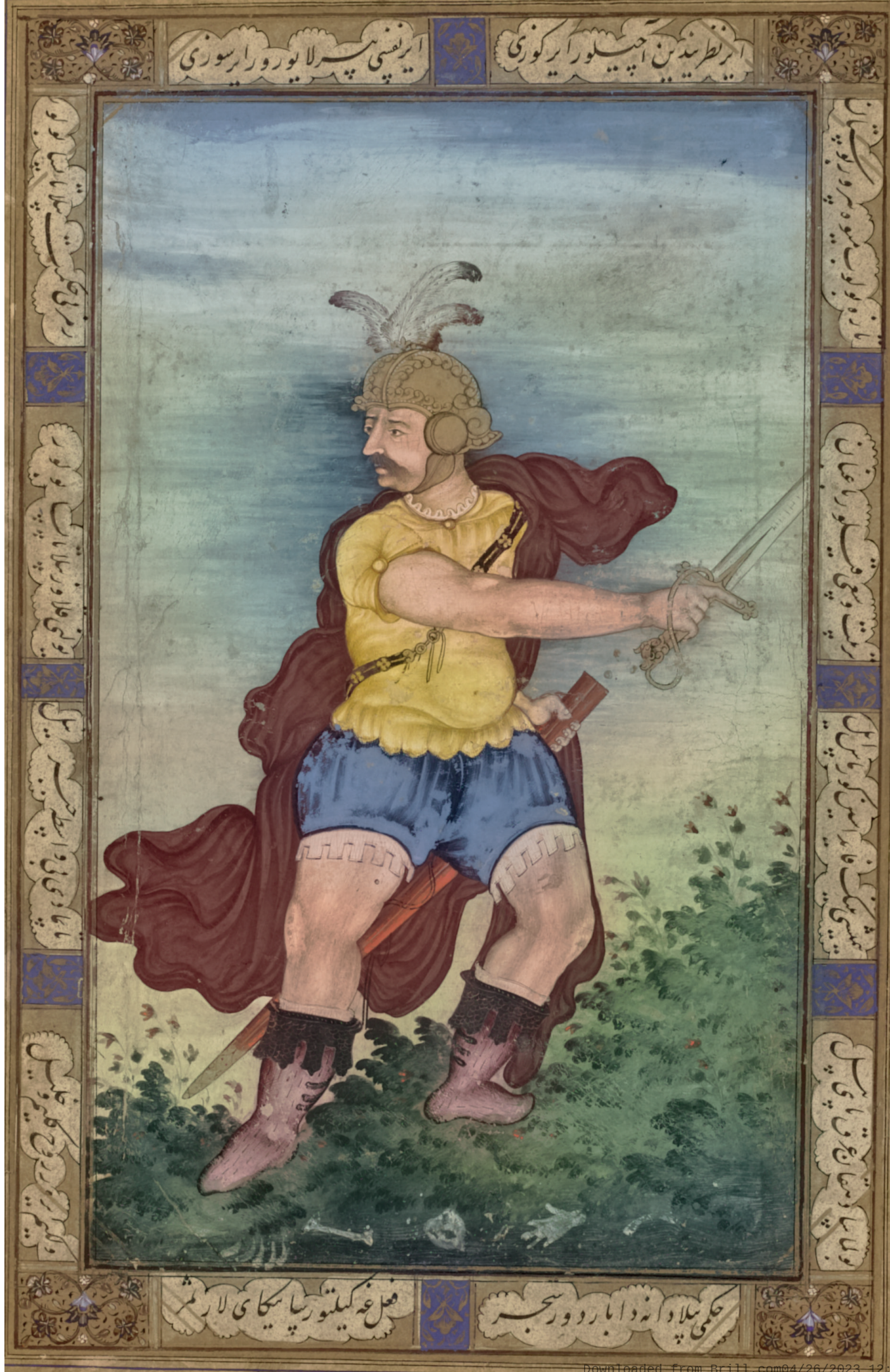

